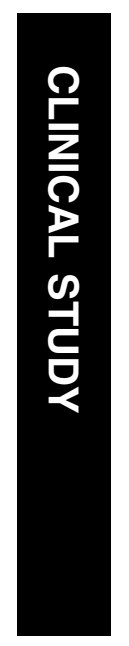

\section{Randomised controlled trial on the effectiveness of lidocaine gel vs tetracaine drops as the sole topical anaesthetic agent for primary pterygium surgery}

${ }^{1}$ Department of

Ophthalmology and Visual Sciences,

The Chinese University of Hong Kong, New Territories, Hong Kong

${ }^{2}$ Department of

Ophthalmology and Visual Sciences,

Prince of Wales and Alice Ho Miu Ling Nethersole

Hospitals, NT, Hong Kong

${ }^{3}$ Department of

Ophthalmology and Visual

Sciences,

Hong Kong Eye Hospital,

Kowloon, Hong Kong

Correspondence: AL Young, Department of

Ophthalmology and Visual Sciences,

The Chinese University of Hong Kong,

Prince of Wales Hospital, Shatin,

New Territories,

Hong Kong.

Tel: + 85226322878 ;

Fax: + 85226482943

E-mail: youngla@

ha.org.hk

Received: 16 April 2008 Accepted in revised form: 19 September 2008 Published online: 7 November 2008

Financial and proprietary interests: None

\section{Abstract}

Purpose To determine the effectiveness of lidocaine $2 \%$ gel $v$ s tetracaine $1 \%$ drops in primary pterygium surgery.

Methods This was a prospective, randomised controlled trial. Forty consecutive patients who had primary pterygium underwent surgical excision of primary pterygium and mitomycin C. Patients were randomised into two groups. Group 1 received tetracaine $1 \%$ drops and solcoseryl eye gel (Solco Basel AG, Switzerland). Group 2 received xylocaine $2 \%$ gel (lidocaine hydrochloride $2 \%$ gel, AstraZeneca, Sweden) topically and normal saline drops $\mathbf{0 . 9 \%}$. Additional tetracaine drops were given to patients who experienced pain preoperatively. The primary outcome was the pain experienced during and after surgery. Immediately after the operation, pain and discomfort scores were assessed by the patients and doctor using a 10-point linear analogue scale. The stages of the operation were divided into the following: stage 1 - first incision, stage 2 - pterygium body excision, stage 3 - conjunctival suturing, and stage 4 -immediate postoperative after patching. Results There was no statistically significant difference in the mean pain scores experienced during pterygium excision $(3.03 \pm 2.35$ for the lidocaine group and $3.98 \pm 2.18$ for the tetracaine group). However, for stage 3 , there was a statistically significant difference in mean pain scores experienced during closure $(P=0.03)(0.47 \pm 0.84$ for the lidocaine gel group and $1.43 \pm 1.66$ for the tetracaine group),
AL Young ${ }^{1,2}$, GYS Leung ${ }^{1,2}$, LL Cheng ${ }^{1,2}$, TTY Lau ${ }^{1,2}$, PTH Lam ${ }^{1,2}$ and DSC Lam $1,2,3$ with patients of group 2 experienced less pain. The mean number of additional drops required by the eyes in lidocaine gel group was also significantly $(0.16 \pm 0.11)$ less than the tetracaine group $(0.67 \pm 0.09, P=0.001)$.

Conclusions Topical administration of lidocaine $2 \%$ gel or tetracaine $1 \%$ drops are both effective anaesthetic agents for primary pterygium surgery and mitomycin $C$.

However, lidocaine gel is superior to tetracaine eye drops and its application is more convenient with a less frequent application and a sustained duration of action.

Eye (2009) 23, 1518-1523; doi:10.1038/eye.2008.319; published online 7 November 2008

Keywords: pterygium; lidocaine gel; mitomycin $\mathrm{C}$ and tetracaine drops; topical anaesthesia

Introduction

Pterygium is a common disease worldwide (5-15\% prevalence), being especially prevalent in the tropics. Clinically, it is a triangular-shaped growth of abnormal subconjunctival tissue that extends horizontally from the bulbar conjunctiva, across the limbus, and onto the cornea. ${ }^{1}$ It is believed to be related to ultraviolet light exposure.

Simple pterygium surgery excision is associated with high rates of recurrence, reported to vary between 29.2 and $88.9 \%$. $^{2,3}$ To improve the outcome, various adjunctive modalities have been described with the aim to reduce recurrence rates. Antimitotic agents employed would include $\beta$-irradiation and 
mitomycin $\mathrm{C}(\mathrm{MMC}){ }^{2} \mathrm{MMC}$ is an alkylating agent that acts by inhibiting fibrovascular growth in the subconjunctival space. ${ }^{4,5}$ Conjunctival graft variations would include conjunctival-limbal autograft, amniotic membrane graft, and conjunctival rotational autograft. ${ }^{3}$

Pterygium surgery is most commonly performed under a local anaesthetic, such as retrobulbar or peribulbar injections. Avoidance of the risks of regional anaesthesia is the advantage of this approach, but it is offset by the need for patient's cooperation and the fact that some discomfort is inevitably felt during the procedure. Other modes of anaesthesia include topical anaesthesia and subconjunctival injections are used to achieve an anaesthetic effect during pterygium surgery. ${ }^{6}$ A variety of anaesthetic agents and formulations have also been used. Frucht-Perry applied topical benoxinate $0.4 \%$ drops and reported its usefulness as an anaesthetic for pterygium surgery. ${ }^{7}$

Lidocaine $2 \%$ gel (lidocaine hydrochloride $2 \%$ gel, AstraZeneca, Sweden) is a commonly used anaesthetic agent for a variety of medical and surgical procedures. In recent years, its safety and effectiveness have been shown in laser treatment, chalazion surgery, cataract, glaucoma, and squint surgery. ${ }^{8-12}$ The gel formulation has the potential advantage of increasing the contact time with ocular tissues, providing a sustained release of lidocaine over a prolonged period.

Subconjunctival lidocaine $2 \%$ solution has been compared to lidocaine $2 \%$ gel topically in patients receiving conjunctival autograft for primary pterygium. ${ }^{13}$ There was no significant difference in mean pain scores of the same drug applied in a different manner. However, lidocaine $2 \%$ gel was found to be effective for the control of pain experienced after pterygium surgery. ${ }^{14}$

We have published our data on a series of patients who underwent pterygium surgery and limbal conjunctival autograft surgery under lidocaine $2 \%$ gel. ${ }^{15}$ The results were promising, hence the current randomised controlled trial was conceived. At the time of the study, there was no prior study comparing the effect of lidocaine gel to another topical anaesthetic agent for pterygium surgery.

\section{Patients and methods}

Consecutive patients scheduled to undergo primary pterygium surgery at Prince of Wales Hospital were recruited. Exclusion criteria were deafness, recurrent or double-head pterygium, history of scleritis or autoimmune diseases, previous ocular surgery, patients receiving regular analgesics, known drug allergy to either lidocaine or tetracaine, and dementia or mental instability. Ethical approval was granted by the Institutional Review Board and the informed consent for study was obtained from all 40 patients.
Patients were randomly assigned into two groups (Figure 1): regimen $\mathrm{A}$ - tetracaine 1\% drops and solcoseryl eye gel (Solco Basel AG, Switzerland-a clear gel similar in appearance to the lidocaine gel) and regimen $\mathrm{B}$-lidocaine $2 \%$ gel (lidocaine hydrochloride $2 \%$ gel, AstraZeneca, Sweden), and normal saline drops $0.9 \%$. One drop of the allocated eye drop was applied three times every $5 \mathrm{~min}$ for the first $15 \mathrm{~min}$. Then, $1 \mathrm{ml}$ of the allocated eye gel was administered once $5 \mathrm{~min}$ before surgery began. The allocated eye drop and gel were administered once more at the beginning of the surgery and when the body of the pterygium was excised. We anticipated potential pain during actual pterygium excision, hence the addition of medications at this stage. If the patients experience any pain during the procedure, upon request, tetracaine $1 \%$ drops were added and the number of drops required were recorded. If the patients become intolerant to the surgery despite above measures, injectional anaesthesia would be offered. All operations were performed as an outpatient basis by one of the authors (AY). None of the patients received preoperative or intraoperative sedation. All the patients and the surgeon were masked to the type of gel and drops used.

After the pterygium was removed, $0.02 \mathrm{mg} / \mathrm{ml} \mathrm{MMC}$ was applied to the undersurface of the conjunctival edge and over the bare sclera for $5 \mathrm{~min}$. Thorough irrigation with $150 \mathrm{ml}$ normal saline was performed thereafter. The conjunctiva was refashioned and sutured with $8 / 0$ Vicyl $^{\circledR}$ (Ethicon, Edinburgh, UK).

The primary outcome of interest was the pain experienced during surgery and postoperatively. The pain and discomfort experienced during all four stages (stage 1 - first incision, stage 2 - pterygium body excision, stage 3 - conjunctival suturing, and stage 4-immediate postoperative after patching) were assessed using a 10-point analogue scale. ${ }^{16}$ These two parameters were enquired of separately to avoid confusion between the two sensations. ${ }^{12}$ It is conceivable that the patient may interpret discomfort from the glare of operating theatre lights, or from having to look in one particular direction for a prolonged period, as being painful.

A score of 0 represented no pain at all and a score of 10 represented the worst pain ever. Immediately after the operation, the nurse would assess the pain and discomfort experienced during and after the operation, in the absence of the surgeon. The surgeon was also asked to give his perception on pain control using the same scale. Other outcome measures include the number of additional anaesthetic drops required during surgery. We certify that all applicable institutional and governmental regulations concerning the ethical use of human volunteers were followed during this research. 


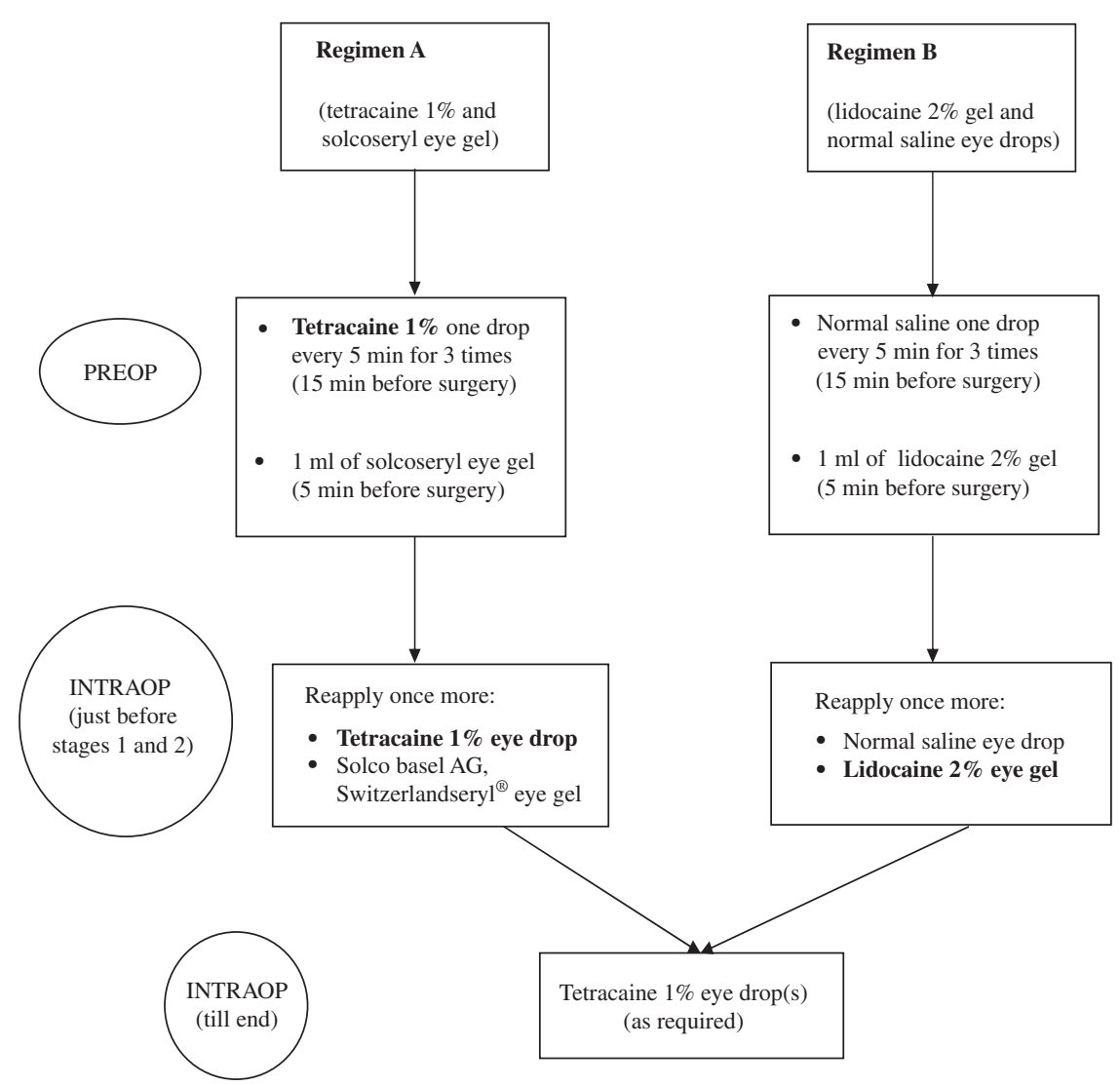

Figure 1 Randomised controlled study on the safety and efficacy of lidocaine $2 \%$ gel $v$ s tetracaine $1 \%$ drop as the sole anaesthetic agent for primary pterygium excision.

\section{Statistical analysis}

Statistical analysis was performed using Student's $t$-test, and the $P$-values less than 0.05 were considered statistically significant. The SPSS (version 11.5) software program was used for the calculations. On the basis of the expected SD of 1.7 for the visual analogue pain scale and an expected effect difference in scoring of at least 2, the calculated target sample size was 40 patients. ${ }^{12}$

\section{Results}

A total of 40 patients (22 females and 18 males) were studied. The patients ranged from 26 to 79 years (mean $60.80 \pm 11.97$ years). There were 12 female and nine male patients in the tetracaine group, and 10 female and nine male patients in the lidocaine gel group. The mean surgical duration for regimen A was $25.33 \pm 5.29 \mathrm{~min}$, and $24.21 \pm 4.85 \mathrm{~min}$ for regimen B. There was no statistically significance difference in mean age, sex, size, and surgical duration between two groups $(P>0.05$, Student's $t$-test; Table 1).
From the patients' perspective, the mean pain score for stage 2 was $3.98 \pm 2.18$ in the tetracaine group and $3.03 \pm 2.35$ for the lidocaine gel group (Table 2). There was no significant difference in mean pain scores experienced at stage 2 . The mean pain scores at stage 3 were less. The mean pain score was $1.43 \pm 1.66$ and $0.47 \pm 0.84$ ( $P=0.03$, Student's $t$-test $)$ for the tetracaine group and gel group, respectively. However, in stage 3, there was a statistically significant difference in the mean pain scores $(P<0.05)$.

From the surgeon's point of view, the subjective pain score at stage 2 was $2.84 \pm 1.07$ for eyes receiving lidocaine gel and $4.52 \pm 1.03$ for eyes receiving tetracaine drops (Table 3). There was a statistical significant difference in the mean pain scores for all the stages.

For the tetracaine group, in 10 out of the 21 cases, no additional tetracaine was required. Eight cases required one additional drop of tetracaine and three cases required two addition drops of tetracaine. In the lidocaine group, there were 16 out of the 19 cases in which no additional tetracaine drops were added. Only three eyes required the addition of one extra drop. The 
Table 1 Demographic details of patients in the two groups

\begin{tabular}{|c|c|c|c|c|}
\hline & $\begin{array}{l}\text { Tetracaine } 1 \% \text { drop group } \\
\qquad(\mathrm{n}=21)\end{array}$ & $\begin{array}{l}\text { Lidocaine } 2 \% \text { gel group } \\
\qquad(\mathrm{n}=19)\end{array}$ & P-value (Student's t-test) & Combined \\
\hline Age (years) & $62.10 \pm 11.47$ & $59.37 \pm 12.67$ & 0.48 & $60.80 \pm 11.97$ \\
\hline Sex & $\begin{array}{c}\text { Male }=9 \\
\text { Female }=12\end{array}$ & $\begin{array}{c}\text { Male }=9 \\
\text { Female }=10\end{array}$ & & $\begin{array}{c}\text { Male }=18 \\
\text { Female }=22\end{array}$ \\
\hline Nasal/temporal & Nasal $=21$ & $\begin{array}{c}\text { Nasal }=17 \\
\text { Temporal }=2\end{array}$ & & $\begin{array}{c}\text { Nasal }=38 \\
\text { Temporal }=2\end{array}$ \\
\hline Laterality & $\begin{array}{c}\text { Left }=11 \\
\text { Right }=10\end{array}$ & $\begin{array}{l}\text { Left }=11 \\
\text { Right }=8\end{array}$ & & $\begin{array}{c}\text { Left }=22 \\
\text { Right }=18\end{array}$ \\
\hline $\begin{array}{l}\text { Size (length in } \mathrm{mm} \text { ) } \\
\text { Size (width in } \mathrm{mm} \text { ) }\end{array}$ & $\begin{array}{l}3.93 \pm 1.11 \\
5.36 \pm 1.60\end{array}$ & $\begin{array}{l}3.87 \pm 1.19 \\
5.55 \pm 0.97\end{array}$ & $\begin{array}{l}0.87 \\
0.68\end{array}$ & $\begin{array}{l}3.90 \pm 1.13 \\
5.45 \pm 1.32\end{array}$ \\
\hline
\end{tabular}

Table 2 Subjective mean pain scores of patients recorded for the four stages

\begin{tabular}{lccc}
\hline Stages & Tetracaine 1\% drop $(\mathrm{n}=21)$ & Lidocaine $2 \%$ gel $(\mathrm{n}=19)$ & P-value (Student's $\mathrm{t}$-test) \\
\hline Stage 1 & $0.71 \pm 1.10$ & $0.53 \pm 1.07$ & 0.59 \\
Stage 2 & $3.98 \pm 2.18$ & $3.03 \pm 2.35$ & 0.19 \\
Stage 3 & $1.43 \pm 1.66$ & $0.47 \pm 0.84$ & 0.03 \\
Stage 4 & $1.10 \pm 1.48$ & $0.42 \pm 0.69$ & 0.078 \\
\hline
\end{tabular}

Table 3 Subjective mean pain scores by surgeon for the four stages

\begin{tabular}{lccc}
\hline Stages & Tetracaine 1\% drop $(\mathrm{n}=21)$ & Lidocaine 2\% gel $(\mathrm{n}=19)$ & P-value (Student's $\mathrm{t}$-test) \\
\hline Stage 1 & $1.76 \pm 0.99$ & $1.11 \pm 0.94$ & 0.039 \\
Stage 2 & $4.52 \pm 1.03$ & $2.84 \pm 1.07$ & 0.0005 \\
Stage 3 & $2.24 \pm 0.62$ & $1.11 \pm 0.81$ & 0.0005 \\
Stage 4 & $1.14 \pm 0.48$ & $0.32 \pm 0.48$ & 0.0005 \\
\hline
\end{tabular}

mean number of additional drops required by the eyes in lidocaine gel group was significantly $(0.16 \pm 0.11)$ less than the tetracaine group $(0.67 \pm 0.09, P=0.001)$. In addition, there were no observed corneal epithelial or ocular surface complications for both groups.

\section{Discussion}

Pterygium excision is a relatively simple, ambulatory procedure performed by many ophthalmologists.

Anaesthesia for excision of pterygium could be achieved by retrobulbar or peribulbar anaesthesia injection.

However, serious complications from injections have been reported. ${ }^{17,18}$ Another option is to apply subconjunctival injection. However, disadvantages such as haemorrhage and swelling of the tissue may obscure the surgical field and plane, trauma to the muscle or muscle sheath and incidental perforation of the globe had been reported. ${ }^{16}$
Avoidance of injectional anaesthesia in ocular procedures has gained popularity in recent years. Many cataract surgeons have replaced the traditional methods of retrobulbar and peribulbar injection with topical anaesthesia. ${ }^{10}$ Pterygium surgery is an extraocular procedure and thus should be suitable for topical anaesthesia. Application of topical anaesthesia for pterygium has many advantages: (1) it does not require a physician to apply the anaesthetic, and thus the conservation of precious theatre time, (2) patients subjectively feel more comfortable without the need for an injection 'to the eye,' (3) voluntary eye movements are preserved throughout the surgery allowing for appropriate surgical positioning directed by surgeon, and (4) the anatomy and tissue planes remain undisturbed allowing precise visualisation, handling, and dissection of tissues.

Frutch-Pery applied benoxinate $0.4 \%$ for pterygium surgery. ${ }^{7}$ However, one drop every minute for $10 \mathrm{~min}$ preoperatively was needed, together with the frequent 
addition of drops (every $5 \mathrm{~min}$ ) was required throughout the procedure. The administration of this number of drops is rather cumbersome and inconvenient.

On the other hand, lidocaine $2 \%$ gel is a widely used agent for topical anaesthesia in urogenital and skin procedures; and has also been applied in ophthalmology for trabeculectomy, corneal graft, and cataract surgery. ${ }^{10,19-22}$ All of our patients completed the operations with their designated treatment. None of the patients in lidocaine or tetracaine group required reversion to conventional injection anaesthesia because of inadequate anaesthesia. As per the normal practice at our centre, no sedation was given to any of our patients. As a result, patient recall of discomfort or pain experienced during surgery would not be affected.

The pain scores appeared to be relatively high for both groups. As this is the first randomised study to compare the effectiveness of lidocaine gel to topical drops, other pain scores for direct comparison are limited. However, previous report on pain scores of subconjunctival injection of lidocaine solution $v$ s topical lidocaine gel yielded a mean pain score of $4.0 \pm 1.01$ in the gel group. ${ }^{13}$ Our mean score of $3.03 \pm 2.35$ for the lidocaine group during pterygium excision is less than previously reported. In addition, the pain scores of both lidocaine gel studies were higher than strabismus surgery with a reported mean pain score of 2.6. ${ }^{12}$

All the scores of the patients were obtained immediately after the operation in the recovery area by the theatre nurse. The surgeon would also fill in the data sheet separately in the surgeon's room immediately after the operation. In this manner, the risk for bias in the surgeon being able to listen to the patients' answers was thus avoided.

The two groups were comparable in age, group size, and sex distribution. Contrary to our expectation as per our experience in squint surgery, ${ }^{12}$ to our surprise, there was no significant difference in patient pain scores for stage 2. This may be attributable to the following reasons: (1) the operations were relatively simple and fast without the need to harvest any conjunctival graft, (2) during the procedure, the 'top-up' application of the designated anaesthetic agents was given just before the excision of pterygium, and (3) the additional drops were given 'on demand' to the patient may also have prevented pain that would be experienced otherwise. However, for stage 3 during suturing of conjunctival wound, there was a statistically significant difference in mean pain scores. This is likely to be related to the gel formulation with an increased contact time with the ocular surface, thereby creating a sustained effect of lidocaine. Another advantage of gel usage is its lubricating effect, obviating the need for corneal wetting during the opeartion. ${ }^{12}$ Lidocaine $2 \%$ gel has been found to be effective for the control of pain in the postoperative period. ${ }^{14}$ Our study had further demonstrated that topical lidocaine $2 \%$ gel is also safe and effective for anaesthesia for primary pterygium surgery.

The disadvantages of tetracaine drops would include the requirement of several administrations before and during the operation, its relatively short contact time, and the potential for cumulative toxicity. However, we did not observe any corneal epithelial or ocular surface complications, either during or after surgery in either group.

In conclusion, both topical lidocaine $2 \%$ gel and tetracaine $1 \%$ eye drop may be considered effective and safe anaesthetics for pterygium surgery. However, the number of supplementary anaesthetic drops required is much less for lidocaine. Furthermore, lidocaine 2\% gel has the additional advantage of application convenience, sustained action, and lubricating effects. 'Needle-free' anaesthesia would be appealing to patients who may be distressed by ocular injections and avoidance of all injection-related complications and injuries.

\section{Acknowledgements}

We wish to acknowledge Dr Patrick MK Tam for his kind assistance in statistical analysis.

\section{References}

1 Karukonda SR, Thompson HW, Beuerman RW, Lam DS, Wilson R, Chew SJ et al. Cell cycle kinetics in pterygium at three latitudes. Br J Ophthalmol 1995; 79(4): 313-317.

2 Adamis AP, Starck T, Kenyon KR. The management of pterygium. Ophthalmol Clin North Am 1990; 3: 611.

3 Prabhasawat P, Barton K, Burkett G, Tseng SC. Comparison of conjunctival autografts, amniotic membrane grafts, and primary closure for pterygium excision. Ophthalmology 1997; 104: 974-985.

4 Lam DS, Wong AK, Fan DS, Chew S, Kwok PS, Tso MO. Intraoperative mitomycin $C$ to prevent recurrence of pterygium after excision: a 30-month follow-up study. Ophthalmology 1998; 105(5): 901-904.

5 Young AL, Leung GY, Wong AK, Cheng LL, Lam DS. A randomised trial comparing $0.02 \%$ mitomycin $C$ and limbal conjunctival autograft after excision of primary pterygium. Br J Ophthalmol 2004; 88(8): 995-997.

6 Smith RB, Everett WG. Physiology and pharmacology of local anesthetic agents (anesthesia in ophthalmology). Int Ophthalmol Clin 1973; 13: 56-59.

7 Frucht-Pery J. Topical anesthesia with benoxinate $0.4 \%$ for pterygium surgery. Ophthalmic Surg Lasers 1997; 28(3): 219-222.

8 Kwok AK, Young AL, Lam DS. Efficacy of lignocaine gel for outpatient laser treatment in inflamed eyes. Eye 2001; 15(pt5): 608-611.

9 Li RT, Lai JS, Ng JS, Law RW, Lau EM, Lam DS. Efficacy of lignocaine $2 \%$ gel in chalazion surgery. Br J Ophthalmol 2003; 87(2): 157-159.

10 Bardocci A, Lofoco G, Perdicaro S, Ciucci F, Manna L. Lidocaine $2 \%$ gel $v$ s Lidocaine $4 \%$ unpreserved drops for 
topical anesthesia in cataract surgery. Ophthalmology 2003; 110: 144-149.

11 Lai JS, Tham CC, Lam DS. Topical anesthesia in phacotrabeculectomy. J Glaucoma 2002; 11(3): 271-274.

12 Yu CB, Wong VW, Fan DS, Yip WW, Lam DS. Comparison of lidocaine $2 \%$ gel $v$ s amethocaine as the sole anesthetic agent for strabismus surgery. Ophthalmology 2003; 110(7): 1426-1429.

13 Oksuz H, Tamer C. Efficacy of lidocaine 2\% gel in pterygium surgery. Acta Ophthalmol Scand 2005; 83: 206-209.

14 Oksuz H, Tamer C. Pain relief after pterygium surgery with viscous lidocaine. Ophthalmologica 2006; 220: 323-326.

15 Leung GY, Young AL, Wong AK, Rao SK, Lam DS. Efficacy of $2 \%$ lignocaine gel in pterygium surgery. Acta Ophthalmol Scand 2006; 84(3): 445.

16 Hay A, Flynn Jr HW, Hoffman JI, Rivera AH. Needle penetration of the globe during retrobulbar and peribulbar injections. Ophthalmology 1991; 98: 1017-1024.

17 Davis DB, Mandel MR. Peribulbar anaesthesia: a review of technique and complications. Ophthalmol Clin North Am 1990; 3: 101-110.
18 Duker JS, Belmont JB, Benson WE, Brooks Jr HL, Brown GC, Federman JL et al. Inadvertent globe perforation during retrobulbar and peribulbar anaesthesia. Patient characteristics, surgical management and visual outcome. Ophthalmology 1991; 98: 519-526.

19 Song SH, Kim JK, Song K, Ahn H, Kim CS. Effectiveness of local anaesthesia techniques in patients undergoing transrectal ultrasound-guided prostate biopsy: a prospective randomized study. Int J Urol 2006; 13(6): 707-710.

20 Taddio A, Gurguis MG, Koren G. Lidocaine-prilocaine cream $v s$ tetracaine gel for procedural pain in children. Ann Pharmacother 2002; 36(4): 687-692. Review.

21 Zabriskie NA, Ahmed IK, Crandall AS, Daines B, Burns TA, Patel BC. A comparison of topical and retrobulbar anesthesia for trabeculectomy. J Glaucoma 2002; 11: 306-314.

22 Segev F, Voineskos AN, Hui G, Law MS, Paul R, Chung F et al. Combined topical and intracameral anesthesia in penetrating keratoplasty. Cornea 2004; 23(4): 372-376. 